\section{THE THYROID GLAND AND HEART DISEASE *}

BY

O. BRENNER, M.D., M.R.C.P.

ASSISTANT PHYSICIAN, AND PHYSICIAN IN CHARGE OF THE CARDIOGRAPHIC DEPARTMENT, UNITED (QUEEN'S) HOSPITAL, BIRMINGHAM

It has been known for many years that there is a close relation between abnormal thyroid function and heart disease, and, indeed, when exophthalmic goitre was first recognized it was thought to be a disease of the heart. In recent years there has been much investigation into the nature of this relation. The detection and treatment of the abnormal thyroid function underlying the cardiovascular abnormality is of fundamental importance, as a direct attack on the cardiac condition is usually ineffective. In the last few years evidence has also accumulated to show that artificial lowering of a previously normal thyroid function may be beneficial in cases of heart disease not associated with abnormal thyroid function. The subject-matter of this address therefore falls naturally into three portions-namely, (1) the heart in thyrotoxicosis: (2) the heart in myxoedema ; and (3) the treatment by thyroidectomy of heart failure in patients without thyrotoxicosis.

\section{THE HEART IN THYROTOXICOSIS}

Increased activity of the thyroid gland such as occurs in exophthalmic goitre results in increased metabolism, which implies that the tissues use more oxygen in unit time, and that they therefore must be supplied by more oxygen from the circulating blood. This may be done in two ways: the output of the heart may increase, or the tissues may abstract more oxygen from each unit of blood passing through them. If the heart is normal it is the first mechanism which is chiefly used, and it is established that the output of the heart per minute varies directly with the rate of metabolism. The second mechanism is only used in fairly advanced heart failure, when the heart is unable to increase its output sufficiently. It may be taken that in patients with normal or only slightly diseased hearts when thyrotoxicosis occurs the resting output of the heart per minute is increased in proportion to the increase in the basal metabolic rate (B.M.R.), so that with the patient at complete rest in bed the heart may be working as hard as if he were walking continuously at a rate of four miles per hour for twenty-four hours every day. Moreover, in thyrotoxicosis the body is an inefficient machine, so that on exertion there is a disproportionate rise in oxygen consumption above the already high resting level, with a corresponding excessive increase in the heart's work above the high basal level. The increased cardiac activity, though necessary to supply the required amount of oxygen to the tissues, is not altogether due directly to an increased call from the tissues, but in part, at least, to an increase in the intrinsic metabolism of the heart itself. ${ }^{2} 18$ s0 The excised hearts of animals fed on thyroid continue to beat more rapidly than normal outside the body, and on section of the bundle, of His, producing complete heart-block, the rate of the isolated ventricle is greater than normal. Even tissue cultures of heart muscle fibres of the embryo chick beat more quickly under the influence of thyroxine. The increased intrinsic metabolism of the heart is shown by the greater oxygen consumption of the hearts of thyroid-fed animals. This makes the heart more susceptible to injury; and cutting off of the oxygen supply ${ }^{*} \mathrm{~A}$ post-graduate lecture given at the Queen's Hospital, Birmingham, on May 31st, 1935. or the accumulation of lactic acid results much more quickly in the cessation of the contractions of the isolated heart.

The heart's output may be increased by an increase in rate or by an increased output per beat. In thyrotoxicosis both methods are used. Tachycardia is one of the cardinal symptoms of exophthalmic goitre, and is present in practically every case. There is no simple method of estimating the output of the heart per beat in man, but in any individual it may be taken as roughly proportionate to the pulse pressure. The diastolic pressure is a measure of the peripheral resistance to the blood flow, and the extent to which the blood pressure rises above the diastolic level during systole depends on the volume of blood thrown at each beat into the aorta. Of course other factors, such as the capacity and elasticity of the arteries, are also involved, but these presumably remain constant over short periods for any one individual. In most cases of thyrotoxicosis there is an increase in the pulse pressure, with a slight rise in the systolic and a slight fall in the diastolic pressure. So close is the relation between the pulse rate and pulse pressure and the cardiac output on the one hand, and between the cardiac output and the metabolic rate on the other hand, that often a close approximation to the true metabolic rate can be arrived at by using Read's formula, which in round figures is as follows: B.M.R. equals $3 / 4$ (pulse rate plus $3 / 4$ pulse pressure) minus 72 .

\section{Clinical Features}

The effect on the heart of this increase in its work depends partly on its condition before the onset of thyrotoxicosis. There is always overaction of the heart, usually immediately evident on examining the chest, and felt by the patient as palpitation, particularly on emotion or exertion. The overaction may impart a slight vibration to the apex beat, which may be mistaken for a slight presystolic thrill and murmur, and it often also makes the heart appear to be larger than it actually is, though it sometimes really is somewhat enlarged in long-standing cases, even in the absence of independent heart disease. No doubt this enlargement, which can be reproduced in animals fed on thyroid, is due to the long-continued cardiac overwork. Necropsy statistics (which, however, include chiefly the worst cases) show slight cardiac enlargement with hypertrophy and dilatation of all the chambers, but especially of the left ventricle, in $\mathbf{5 0}$ to 60 per cent. of all cases uncomplicated by independent heart disease. ${ }^{30} 3840$ The $x$-ray shows cardiac enlargement in 30 to 45 per cent. of all cases of thyrotoxicosis. ${ }^{1} 143138$ It is commonest in the older patients, and in those with auricular fibrillation, heart failure, and independent heart disease. It is rare in young patients without auricular fibrillation or independent heart disease. ${ }^{1}$ The enlargement is chiefly to the left; the pulmonary arc is somewhat prominent; there is little prominence of the right auricle; and the left auricle, in the oblique view, is normal. ${ }^{38}$ When once cardiac enlargement has occurred it seems to be permanent, there being no significant change in the heart's size after successful partial thyroidectomy. ${ }^{44}$

\section{AURICULAR FIBRILLATION}

Auricular fibrillation ultimately supervenes in many cases of thyrotoxicosis, and was present in eleven out of fifty-three cases (21 per cent.) electrocardiographed at the Queen's Hospital in the last three years. This proportion is too high, as some cases with a regular rhythm were not electrocardiographed. During this period there were 115 cases of auricular fibrillation, so that a diagnosis of thyrotoxicosis was made in about 10 per cent. of all cases of auricular fibrillation. Various observers report auricular 
fibrillation in 6 to 27 per cent. of cases of thyrotoxicosis. It arises proportionately twice as frequently in males as in females, and its incidence increases with the patient's age and with the duration of the disease. It also appears transiently after thyroidectomy in 7 per cent. of patients with previously normal rhythm. ${ }^{21}$ It has been suggested that the liability of the thyrotoxic heart to develop auricular fibrillation is due to an increased susceptibility to the action of adrenaline, since in thyroidfed rabbits an injection of adrenaline often caused the onset of auricular fibrillation..$^{45}$ Fibrillation is frequently accompanied by marked cardiac enlargement and heart failure, and in most cases of thyrotoxic heart failure fibrillation is present. Other abnormalities in rhythm are rather uncommon. Auricular flutter was found in one series in 2 per cent. of cases. ${ }^{14}$ Extrasystoles may occur, though in non-thyrotoxic tachycardia they are rare. Groodall $^{28}$ found a prolonged P-R interval (partial heartblock) in 30 per cent. of cases, but this has not been confirmed. Occasional cases with complete heart-block have been described, ${ }^{16}$ but this was always due to independent heart disease.

\section{CARDIAC FAILURE}

In many cases congestive heart failure with dyspnoea, cyanosis, gross oedema, etc., ultimately develops, while angina pectoris is less common. ${ }^{1.43} 34$ That the relation of these symptoms to the abnormal activity of the thyroid gland is intimate is shown by the dramatic recovery which almost invariably takes place after successful subtotal thyroidectomy; but evidence is accumulating to show that thyrotoxicosis is not the only factor. In some patients the most severe and even fatal thyrotoxic crises may arise without the least sign of heart failure, while in others the presenting symptoms may be those of heart failure, and the evidence of thyrotoxicosis may readily be missed. Heart failure supervenes more commonly in cases of " toxic adenoma" (with a nodular goitre, often inconspicuous eye signs of Graves's disease, only slight wasting, and slight elevation of the B.M.R.) than in cases of " primary exophthalmic goitre" (with uniform thyroid enlargement, marked eye signs, rapid wasting, and a high B.M.R.), in which there may be no symptoms of heart failure. The difference is so striking that it has even been suggested that the thyroid adenomata produce a toxin which specifically damages the heart. It has been amply demonstrated, however, that "toxic adenoma" is merely the chronic stage of exophthalmic goitre, which is a disease with periodic remissions and exacerbations. In the remissions the gland undergoes involution, which in some parts is excessive, in others incomplete. These areas of hyper- and hypo-involution are specially involved in successive exacerbations, and progressively enlarge, with compression and fibrosis of the surrounding thyroid tissue, to form pseudo-capsules round the " adenomata." o 20234243

The difference in the reaction of the heart in " primary exophthalmic goitre" and "toxic adenoma" is due to a difference in the heart, not in the thyroid. Heart failure chiefly occurs in older patients, and is therefore commonly associated with toxic adenoma, which, being the chronic stage of exophthalmic goitre, is also found in the later age groups. Of seventy-two thyrotoxic patients over the age of $40^{2}$ heart failure was present in twenty-eight (39 per cent.), while in 128 under 40 years of age failure was present in only nine ( 7 per cent.). It is thought that the higher incidence in middle and old age is due to the supervention of independent degenerative cardiovascular disease, particularly coronary artery sclerosis and high blood pressure. The perfectly normal heart is able to stand the strain of the perpetual increase in its work in thyrotoxicosis, but if there is even slight independent cardiovascular disease heart failure takes place. This is supported by the fact that of the nine patients with heart failure under the age of $40^{2}$ five had mitral stenosis, in one there was post-mortern evidence of rheumatic carditis, a seventh had syphilitic aortitis, and in only two could no definite evidence of independent heart disease be obtained. Again, in twentyseven cases of thyrotoxicosis ${ }^{40}$ examined post mortem seven patients had died of heart failure, and five of these had gross independent heart disease; while of six patients with independent heart disease five died of heart failure. Auricular fibrillation is also an important factor in causing cardiac failure, which was found in 3 per cent. of cases with a normal rhythm, and in 30 to 60 per cent. of cases with fibrillation. ${ }^{1}$ In the patients with angina pectoris no doubt there is some coronary arteriosclerosis, restricting the volume of blood delivered to the overworked heart.

\section{Pathological Changes in the Heart}

Evidence as to direct damage to the heart has been sought from histological studies after death and from electrocardiographic changes. Goodall ${ }^{28}$ described bundles of necrotic heart muscle fibres infiltrated with round cells, and capillary dilatation with endothelial proliferation. Rake ${ }^{40}$ found similar changes in five of twenty-seven cases, but in three of these there was also rheumatic or syphilitic heart disease. Weller, ${ }^{49}$ in thirty-five cases of uncomplicated thyrotoxicosis, found patches of fibrosis of the heart in 80 per cent. and cellular infiltrations in 31 per cent., but similar changes were observed in controls in 52 per cent. and 17 per cent. of cases respectively. Eight of seventeen thyroid-fed guineapigs $^{40}$ had patches of necrotic heart muscle surrounded by round cells (changes similar to those described by (ioodall), but all of these died of bronchopneumonia. Of the nine without pneumonia, only one had a few small patches of necrosis. The patches of necrotic heart muscle, of which the fibroid patches described by Weller are no doubt the late stage, therefore seem to be due to infection not thyrotoxicosis. The large proportion of normal controls revealing similar changes robs Weller's figures of significance. Thus no cardiac lesion due to thyrotoxicosis has yet been demonstrated, except for moderate cardiac enlargement, no doubt due to persistent overwork.

\section{Electrocardiographic Changes}

Goodall ${ }^{28}$ reported partial heart-block (prolonged P-R interval) in 30 per cent. of cases, but this has not been confirmed, and was found in none of the cases at the Queen's Hospital. Burnett ${ }^{14}$ reported slurred $\mathrm{R}$ waves in 74 per cent. of sixty-two cases, but this, too, has not been confirmed. The changes commonly described are tall $P$ waves and $T$ waves, though these occur in only about 25 per cent. of cases and are often not conspicuous. 192829343538 The $T$ wave may become lower after thyroidectomy, and in myxoedema it is usually flat or inverted. Hamburger ${ }^{29}$ says that tall $P$ and $T$ waves and low $R$ waves indicate high sympathetic tone, not heart disease. The electrocardiographic evidence of direct cardiac damage due to thyrotoxicosis is thus no more conclusive than the pathological. Nevertheless the frequent occurrence of auricular fibrillation is evidence of an important functional change in the heart muscle. That it is not due to structural changes in the heart is shown by the common spontaneous reversion to normal rhythm shortly after successful thyroidectomy.

\section{Blood Pressure}

A slight rise in systolic and slight fall in diastolic pressure is common in thyrotoxicosis. Burnett ${ }^{14}$ says that in 19 per cent. of cases the systolic pressure is over 160 , and in 22 per cent. the diastolic pressure is over 90. Parkinson ${ }^{39}$ has recently reported 100 cases of hyperpiesis in which there was some evidence of thyrotoxicosis. The pulse rate ranged from 90 to 110 , auricular fibrillation was present in twentythree, and there was some thyroid enlargement, usually minimal, in all. The B.M.R. was often high, but it is known often to be raised in high blood pressure in the absence of thyrotoxicosis. Parkinson suggests that thyrotoxicosis may be a cause of hyperpiesis, but it might be objected that the 
evidence of thyrotoxicosis in his cases is so slight, and hyperpiesis after middle age is so common, that the connexion between thyrotoxicosis and hyperpiesis is not proven. Rosenblum $^{44}$ found no significant change in blood pressure in sixty-nine patients after subtotal thyroidectomy, and we found no significant change in seven patients after total thyroidectomy. ${ }^{13}$ Davis ${ }^{17}$ observed in twenty-nine cases after total thyroidectomy that the blood pressure sometimes rose, sometimes fell, sometimes was unchanged. On the other hand, the blood pressure was high in fourteen of thirty cases of myxoedema, and was reduced by thyroid treatment in eleven of these. ${ }^{32}$

It may thus be concluded that there is as yet no certain evidence that thyrotoxicosis directly damages the heart or that it causes hyperpiesis. When heart failure takes place it is due chiefly to the persistent increase in the cardiac work necessitated by the raised B.M.R. ; partly to the development of auricular fibrillation, owing to functional changes in the heart muscle; and partly to the presence of independent cardiovascular disease, usually rheumatic or syphilitic in young patients, and coronary sclerosis or hyperpiesis in older ones, which makes the heart unable to withstand successfully the strain of the perpetual increase in its work imposed by the raised B.M.R.

\section{D!agnosis}

In cases of thyrotoxic heart failure diagnosis is particularly important, as there is little response to treatment until the thyrotoxicosis is controlled. Often the signs of thyrotoxicosis (goitre, exophthalmos, wasting, etc.) are inconspicuous. Estimation of the B.M.R. is of comparatively little importance, as in many cases of thyrotoxic heart failure it is not very greatly raised, and it is often somewhat raised in non-thyrotoxic heart failure. ${ }^{36}$ The presence of heart failure in the absence of valvular disease, hyperpiesis, syphilitic aortitis, or electrocardiographic evidence of myocardial degeneration secondary to coronary artery narrowing, should prompt a careful search for evidence of thyrotoxicosis. Again, auricular fibriliation is usually associated with rheumatic heart disease, coronary arteriosclerosis, or thyrotoxicosis. In the absence of the two former a specially careful search for evidence of thyrotoxicosis should be made. Tachycardia, in the absence of pyrexia, is common in nervous patients, but it disappears during sleep, while in thyrotoxicosis it persists-though at a somewhat lower level-even during sleep. ${ }^{12}$ The presence of numerous extrasystoles in spite of tachycardia is unusual except in thyrotoxicosis. ${ }^{46}$

If suspicion is aroused by any of these points it may be noticed that the eyes are very bright and have a slightly staring expression; or that one eye is slightly more prominent and has a wider palpebral fissure than the other; or a firm nodular thyroid gland may be felt on careful palpation ; or there may be a fine tremor, flushing or pigmentation of the skin, nervousness, loss of weight, etc. The diagnosis may then be confirmed by finding an abnormal B.M.R. The normal range for the B.M.R. is minus 15 per cent. to plus 15 per cent., so that a rate of plus 12 per cent., though within the normal range, may be high for a patient whose normal rate is minus 15 per cent. In such cases there is usually a marked fall in the B.M.R. under the influence of rest and Lugol's iodine, and this is a help in arriving at a diagnosis in a doubtful case. It is also said that while in normal persons and in thyrotoxic patients there is a marked rise in the metabolic rate after a meat meal, there is either no change or actually a fall in patients with non-thyrotoxic heart failure. ${ }^{7}$ This may possibly prove of some value in differentiation from cases of non-thyrotoxic heart failure with a raised B.M.R.

\section{Prognosis}

In the absence of partial thyroidectomy the prognosis is bad. There is usually little or no response to treatment by rest and digitalis when once auricular fibrillation and congestive failure have set in. Digitalis is often unable even to reduce the tachycardia of auricular fibrillation, though in some cases with only slightly raised B.M.R. there may be some reduction in the heart rate. Death is usually due to heart failure, though sometimes to pneumonia or other intercurrent disease. Partial thyroidectomy gives much more hope of improvement or cure, although congestive failure naturally adds greatly to the operative risk, and the operative mortality in the presence of failure has been placed as high as 20 per cent. ${ }^{6}$ The risk of not operating, however, is even greater.

In successful cases there is a dramatic improvement in the congestive failure, which often disappears altogether in a few days. Auricular fibrillation disappears spontaneously in about half the cases after the operation, and in most of the remainder it can be dispelled by a few doses of quinidine. In patients observed for years after successful thyroidectomy there is no further evidence of heart disease unless independent heart disease was previously present. ${ }^{4144}$ The prognosis in cases surviving the operation is thus very good, and the high operative mortality in patients with severe congestive failure is therefore a strong argument for early thyroidectomy in cases of thyrotoxicosis, before heart failure develops.

\section{Treatm.ent}

Partial thyroidectomy is the essential step in treatment, but it is necessary first to get the patient into the best possible condition to stand the operation. He should therefore be kept at complete rest in bed, and should be given 5 to 10 minims of Lugol's iodine in milk thrice daily. This usually leads to temporary improvement in the thyrotoxicosis, and often in the heart failure. If auricular fibrillation is present digitalis leaf ( 1 to 2 grains thrice daily) should be prescribed, though it usually has little effect. Mercurial diuretics (neptal, salyrgan, etc.) should be employed if necessary, as it is undesirable to operate if oedema is still present. After ten to fourteen days of this treatment the patient will usually be as fit for operation as he is ever likely to be, and subtotal thyroidectomy should be performed, with local anaesthesia or a basal hypnotic followed by gas and oxygen. Only a small shaving of the gland should be left on each side, to safeguard the parathyroids and the recurrent laryngeal nerves. It is almost impossible to remove too much gland, as the fragments left always hypertrophy after the operation. In any case slight myxoedema is preferable to persistent hyperthyroidism, as it can be controlled by thyroid extract if necessary.

With adequate pre-operative treatment the operation is usually well borne, and in a few days all signs of heart failure disappear. Auricular fibrillation, if present, disappears spontaneously in about half the cases. If it persists quinidine should be given, beginning not later than a week after the operation. This restores normal rhythm in over 90 per cent. of the cases in which it does not return spontaneously. If the administration of quinidine is delayed there is more risk of the fibrillation proving permanent. ${ }^{1}$ In most cases successfully treated by thyroidectomy the patient may, after a holiday, gradually be allowed to return to full activity without suffering any further inconvenience from her cardiac symptoms.

\section{THE HEART IN MYXOEDEMA}

While the cardiac complications of thyrotoxicosis have been known since hyperthyroidism was first recognized, it has only recently been shown that the heart is usually abnormal in myxoedema. The abnormality reveals itself chiefly by cardiac enlargement and by electrocardiographic changes. The incidence of cardiac enlargement as disclosed by $x$-ray examination has been variously estimated at 20 to 83 per cent. by different observers. ${ }^{32} 37$ In a small 


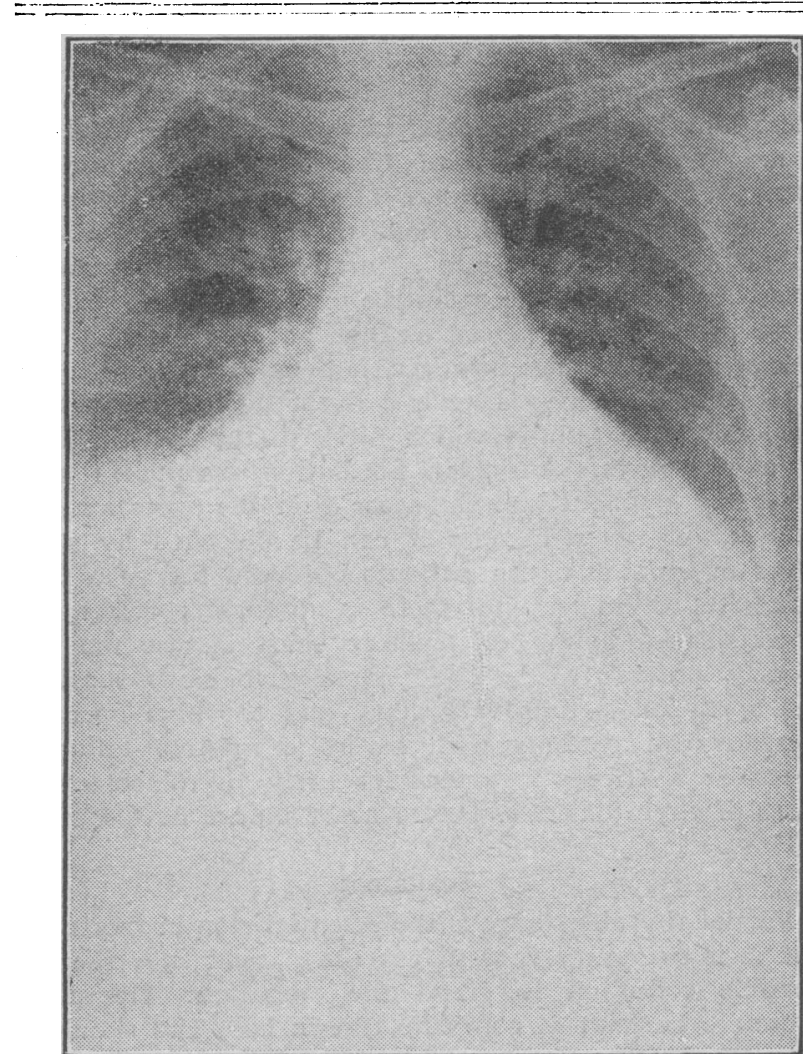

FIG. 1A.- $X$-ray of heart of patient with spontaneous myxoedema, befors treatment, showing narked enlargemer.t.

series of six cases of spontaneous myxoedema personally observed there was cardiac enlargement in all. The heart shrank after treatment by thyroid extract in five. In three the diminution in size under treatment was only moderate, but in two the previously greatly enlarged heart returned almost to normal size (Figs. 1A and 1B). Cardiac enlargement also occurs in artificial myxoedema produced

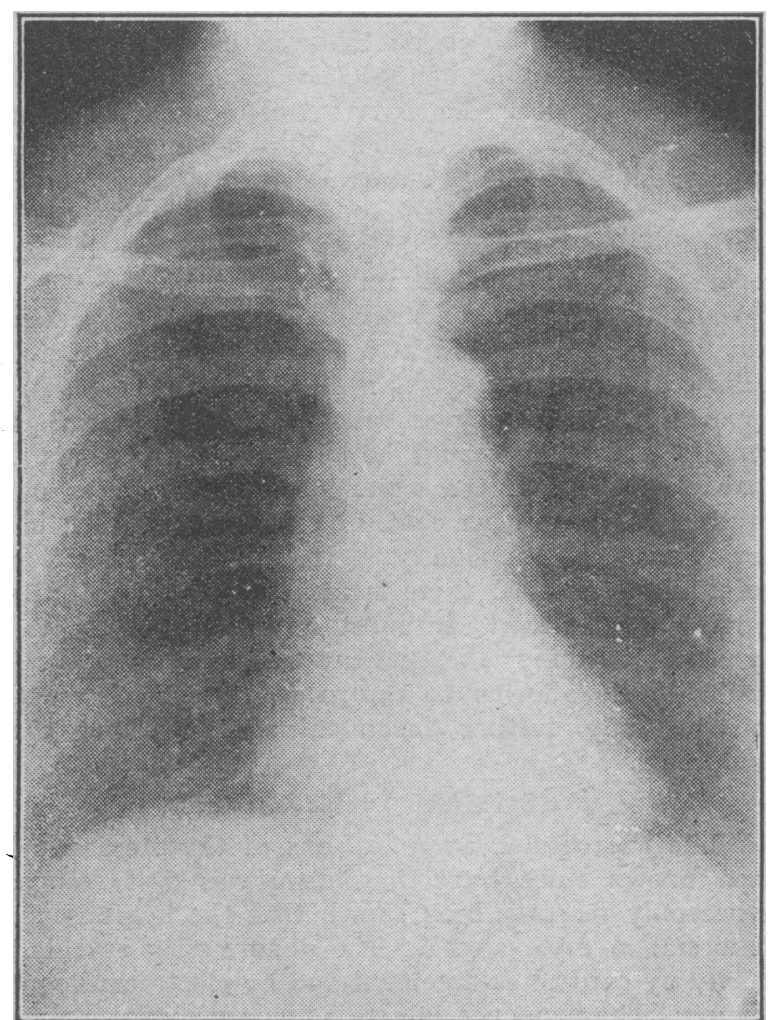

Fliv. 2A.- $X$-ray of heart of patient with hypertension and cursuiry sclerosis, showing slight enlargement.

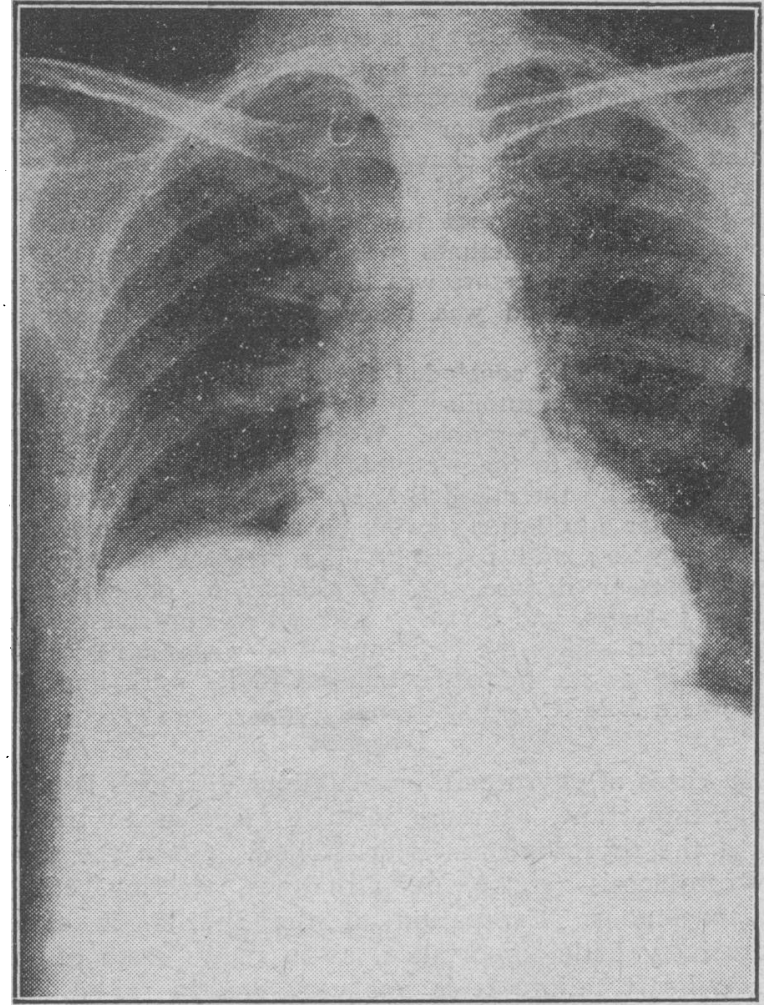

FIG. 1B.-Same patient after control of myxoedema $L:$ hyroid extract, showing diminution in size of heart.

by total thyroidectomy (Figs. 2A and 2B). Lerman ${ }^{32}$ reports that in spontaneous myxoedema the heart shrank by $1 \mathrm{~cm}$. or more in twenty of the twenty-five cases in which it was enlarged, and in four of the remaining five hyperpiesis was present. In some of the recorded cases the heart, which practically filled the chest, returned almost to normal size after treatment. Dilatation of the

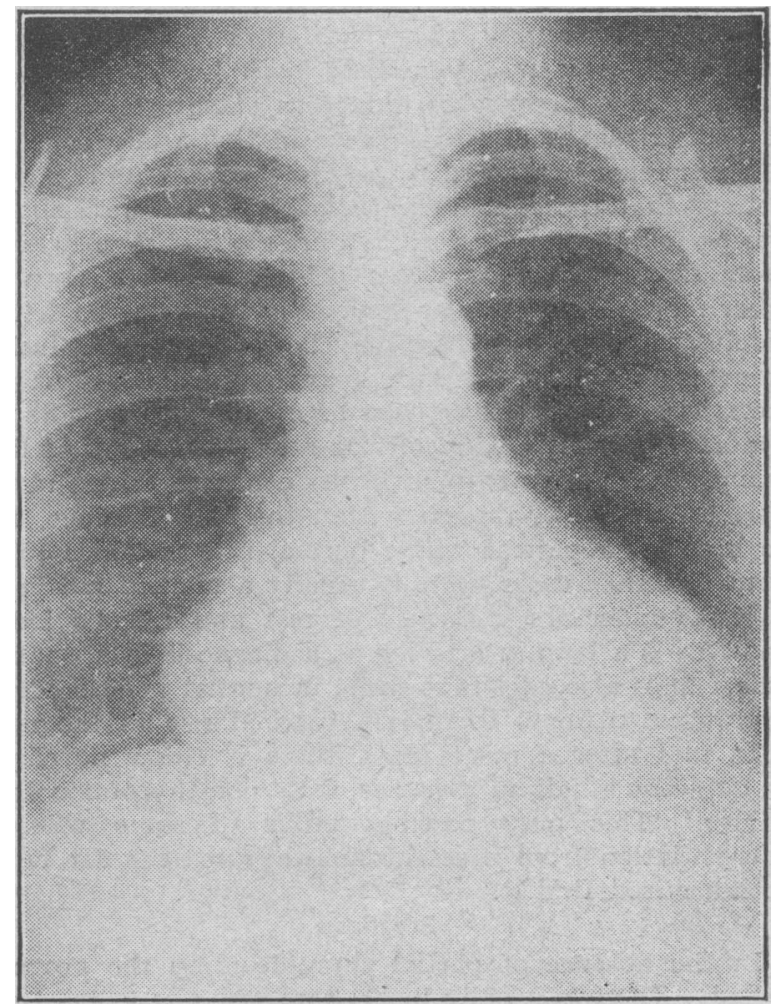

FIG. 2B.-Same patient after total thyroidectomy, showing great increase in heart size coincident with occurrence of myxoedema. Symptoms were greatly improved at this stage. 
heart, myxoedematous changes in the heart muscle, and pericardial effusion have been suggested as possible causes of the enlargement of the cardiac shadow, but no definite conclusion has been reached.

The electrocardiogram typically reveals diminution in the size of all the waves. ${ }^{47}$ The QRS complex is of low voltage, and the $\mathrm{T}$ waves are flat or inverted. Under treatment the $\mathrm{P}$ and $\mathrm{QRS}$ waves become larger, and the $T$ waves become upright. These changes were found in five of the six personal cases of myxoedema (Figs. 3A and $3 \mathrm{~B})$, and the reverse changes (diminution of the voltage of the QRS complex, and flattening or inversion of the $T$-waves) was observed in many of the cases of myxoedema produced by total thyroidectomy. These changes are practically constant in myxoedema. ${ }^{32} 27$ Occasionally the $\mathrm{CRS}$ and $\mathrm{T}$ waves, though low, are within the normal limits; but even here they usually increase in size under treatment. Occasionally there is

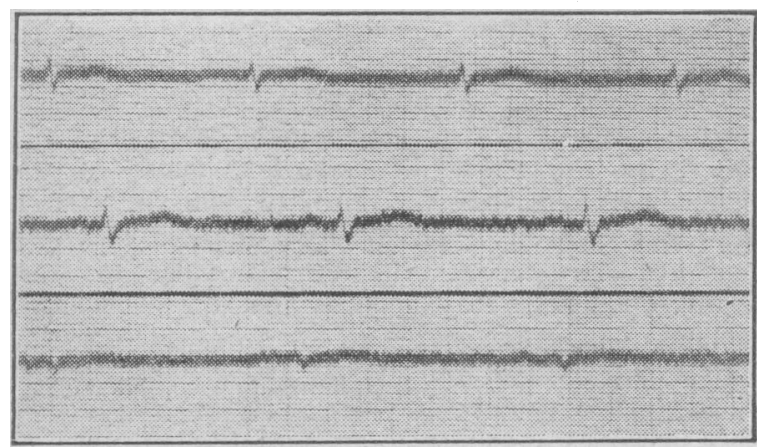

Fig. 3A.-Electrocardiogram of a case of spontaneous myxoedema, showing small $P$ and $Q R S$ waves, and almost flat $\mathrm{T}$ waves.

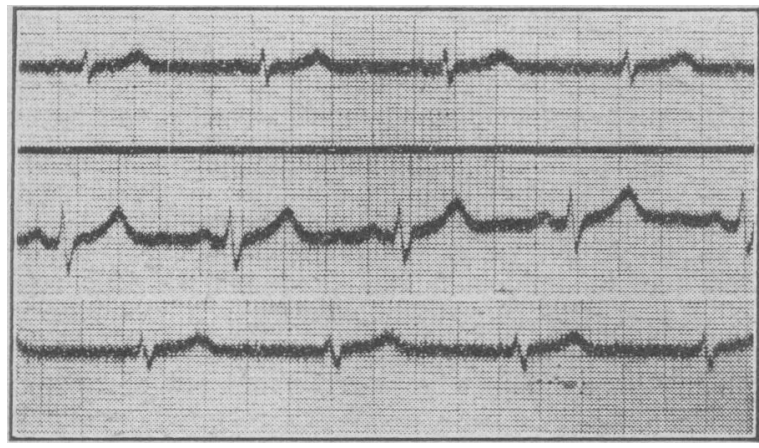

FIG. 3B.- Same case, after control of the myxoedema by thyroid extract, showing well-marked $P$ waves in Lead II, somewhat increased size of the QRS complex in all leads, and well-marked $T$ waves in all leads.

partial heart-block or bundle-branch block, ${ }^{22}{ }^{37}$ which disappear under treatment. The only other constant cardiac signs in myxoedema are a slow pulse and a somewhat low pulse pressure, indicative of a low cardiac output. The blood pressure is sometimes high, ${ }^{32}$ and then often falls, sometimes to normal, under treatment.

\section{Heart Fa:lure}

In spite of the constancy of these changes, cardiac symptoms are unusual, though many patients have slight dyspnoea. It seems likely that the cardiac enlargement and the electrocardiographic changes indicate impaired cardiac efficiency, but at the same time the lowered metabolism and lessened demand of the tissues for oxygen-containing blood allow the heart to diminish its work to a level which it is easily able to maintain, inefficient as it is. Nevertheless, occasional cases of heart failure in myxoedema have been described. In on ${ }^{22}$ treatment by rest and digitalis was ineffective, but the heart failure disappeared under treatment with thyroid extract. When treatment was suspended, heart failure returned as the myxoedema reappeared, but disappeared again when treatment was resumed. This, however, is most unusual. In two of our six cases of spontaneous myxoedema there was ascites, which disappeared under treatment, but there were no other signs of heart failure in this or any of the other cases, and Lerman ${ }^{32}$ found only slight or no signs of heart failure in thirty cases of myxoedema, though cardiac enlargement was present in twenty-five and electrocardiographic changes in all.

Coronary arteriosclerosis is common in myxoedematous patients, and usually causes no symptoms, since the heart does comparatively little work and the narrowed coronary arteries are able to deliver enough blood for its needs. If large doses of thyroid extract are given, metabolism, and with it the heart's work, rapidly increases. The blood flow through the narrowed coronary arteries may then be insufficient, and severe, even fatal, angina may occur. Treatment should therefore be begun with very small doses of thyroid extract, gradually increased. If angina supervenes the dose should be reduced. Occasionally treatment has to be abandoned because of the appearance of severe angina as soon as the metabolic rate begins to rise.

\section{THYROIDECTOMY IN HEART DISEASE}

The dramatic disappearance of thyrotoxic heart failure after subtotal thyroidectomy encouraged certain American workers to try thyroidectomy in the treatment of nonthyrotoxic heart failure. ${ }^{9} 101125$ The rationale is as follows. In failure, the heart is able to maintain a supply of oxygen-containing blood adequate for the needs of the tissues only with great difficulty, or not at all. Thyroidectomy diminishes metabolism and the oxygen consumption of the tissues, so that their demands for oxygen-containing blood are satisfied, and the symptoms of heart failure diminish or disappear.

In less advanced failure the heart is able, with difficulty, to maintain an adequate supply of blood to the tissues, at least during rest, by the mechanism formulated in Starling's law of the heart. This states that the output of the heart in systole varies (within limits), as its size in diastole. Normally, during exercise, the return of blood to the heart is increased and the venous blood pressure rises. This causes distension of the heart during diastole, when the venous blood pressure is transmitted through the open mitral and tricuspid valves to the ventricles, with a correspondingly greater systolic contraction and the expulsion of more blood into the aorta. If the heart is diseased it must be more than normally distended during diastole if it is to expel the normal volume of blood during systole. This distension is produced by a rise in venous blood pressure. In this way, by a progressive rise in venous blood pressure, the cardiac output, at least at rest, can long be kept within normal limits in spite of advanced myocardial disease:

Now a high pulmonary venous pressure, associated with diastolic distension of the left ventricle, is conducted back to the pulmonary capillaries, which are distended, thus encroaching on the pulmonary air space and diminishing the vital capacity "(the greatest possible volume of air expired after the deepest possible inspiration). Dyspnoea occurs when the tidal air (volume of air taken in at each inspiration) exceeds one-third: of the vital capacity. The rise in pulmonary venous pressure may thus make the vital capacity less than three times the tidal air, so that dyspnoea takes place in spite of a normal cardiac output. Similarly; the rise in systemic venous pressure necessary to maintain the normal output of the right ventricle may cause hepatic enlargement, oedema, etc. If the thyroid is removed at this stage the needs of the tissues for oxygen-containing blood are lowered and the heart can reduce its output to below 
the normal level. It can maintain this diminished output without a rise in the venous pressure, so that the distension of the pulmonary capillaries is lessened, the vital capacity is increased, and dyspnoea disappears. There is a similar disappearance of hepatic engorgement and oedema owing to the fall in systemic venous pressure.

\section{In Angina Pectoris}

The argument in angina pectoris is similar. Angina is due to an insufficient supply of blood to the heart through the coronary arteries when the heart's work is increased by exertion or emotion, though the supply is sufficient when the heart is acting quietly. Thyroidectomy so diminishes the work the heart has to do that the amount of blood the coronary arteries are able to deliver is sufficient even during exertion, and the angina disappears. It has been found that the angina disappears almost immediately after the operation, before there is much reduction in the B.M.R., and it has been suggested that though the permanent results are due to the lowered B.M.R. the immediate benefit is due to interruption of the sympathetic sensory fibres from the heart at the time of operation. In support of this it is said ${ }^{48}$ that in patients with pain on both sides of the chest, removal of one lobe of the thyroid relieves the pain only on the same side of the chest.

Exposure of the thyroid to $x$ rays or radium was first tried as a method of reducing thyroid function, but it was soon found that these, in doses harmless to the surrounding structures, had no influence on the normal thyroid. Next, subtotal thyroidectomy was tried, but this proved only temporarily successful, as the thyroid tissue left behind soon regenerates, the B.M.R. rises again, and the condition of the patient is soon as bad as before. Nothing short of removal of the whole thyroid gland ${ }^{8}$ is effective, though naturally this has drawbacks. The patients often develop myxoedema, though this may take months and sometimes never occurs, in spite of a great fall in the B.M.R. ${ }^{27}$ The myxoedema, however, can easily be kept in check by small doses of thyroid extract. Myxoedema is almost always present when the B.M.R. falls below minus 30 per cent. Between minus 30 and minus 20 there. are symptoms only of slight hypothyroidism. Above minus 20 there are no hypothyroid symptoms at all..$^{51}$ The B.M.R. may thus be allowed to fall between minus 20 and minus 30 , with great relief to the heart and without the appearance of serious hypothyroidism. Again, care is necessary to avoid damaging the recurrent laryngeal nerves and removing all the parathyroids. ${ }^{24}{ }_{26}$ In the American series a fall in the serum calcium and slight signs of parathyroid deficiency, without actual tetany, occasionally took place. This was readily controlled by the administration of calcium and a vitamin $D$ preparation for a few days. After this the parathyroids left behind hypertrophy to compensate for those lost.

\section{Selection of Cases}

We have followed substantially the indications set forth by the American originators of the operation. Only patients incapacitated by heart failure or angina, in whom all other treatment has not sufficed to restore a reasonable amount of activity, are subjected to operation. But it is hopeless to operate on moribund patients, or on those with such advanced heart failure that rest, digitalis, diuretics, etc., do not abolish gross oedema. All our patients have had one or more courses of ordinary treatment in hospital, and though oedema has subsided when present, they have been quite unable to work. Angina has persisted in spite of rest in bed and prophylactic nitroglycerin.

Again, the patients must not be suffering from actively progressing heart disease (active rheumatic carditis, active syphilitic aortitis, active coronary sclerosis, with repeated thromboses, etc.). In such cases the rapid deterioration of the heart would quickly nullify the beneficial results of diminishing its work. Finally, the pre-operative B.M.R. must not be below minus 15 per cent., since, owing to the occurrence of myxoedema, the B.M.R. cannot be allowed to fall below minus 30 per cent., and this fall is too slight to produce appreciable benefit. If these indications are observed it will be found that the field for the operation is more restricted than was at first thought would be the case. We have added only one to the series of six reported last year, and another is being prepared for operation. We have recommended operation to three others we considered suitable, who, however, refused it.

\section{Results}

Though the patients all have very grave heart disease, the operative mortality is low. In the American series there were two operative deaths, both in patients practically moribund before operation. In our seven cases there were no operative deaths, and none of them gave cause for anxiety on the operating table or in their postcperative course. Encouraging remote results have been reported by the American observers, many of whose patients have been able to return to light, or even full, work. Our own small series supports these conclusions, though not every case is benefited to a significant degree. One was operated on six months ago, the others twelve to seventeen months ago. Two of the seven patients are dead (Cases 4 and 6 of our previous report)-one six weeks and the other thirteen months after operation. Both died of cerebral haemorrhage (confirmed at necropsy), and in both the blood pressure, before and after operation, was always above 200. In buth the congestive failure and angina were relieved after operation, and in Case 4 (the patient dying thirteen months after operation) the relief was great. Before operation she was unable to do any housework, and was scarcely able to get about. After the operation her cardiac symptoms almost disappeared, and she was soon able to return to full housework, including the heavy household washing. The headache, giddiness, tinnitus, etc., however, still persisted, until she was strack down by the cerebral haemorrhage.

Two patients (Cases 3 and 5 of our previous report) have not greatly improved. In Case 3 (hypertension, coronary sclerosis, congestive failure, and angina) the patient improved somewhat for the first few months after operation, but has since gradually relapsed, presumably because of progress of her heart disease, and she still has severe congestive failure, with orthopnoea, cyanosis, oedema, and ascites. She refuses to go to bed, and her exercise tclerance is slightly better than before operation. She can get about with difficulty, but is unable to work. In Case 5 (old coronary occlusion) the patient was before the operation incapacitated by angina, which did not yield to any treatment. Since the operation the angina is much less 'readily produced, but he is dyspnoeic on exertion, though he can get about more easily and is more comfortable. $\mathrm{He}$ is still unable to work. The patien't operated on six months ago (not included in our previous series) had congestive failure and angina, and was so dyspnoeic that for a month before operation she had been unable to go to bed, and had to sit up in a chair all night. She was unable to walk more than a few steps without being pulled up, either by dyspnoea or pain. She is now much more comfortable, can sleep in comfort propped up on three pillows, can walk slowly upstairs without resting, but is still unable to do any housework. In Case 1 (hypertension, coronary sclerosis, congestive failure, and angina) the patient is much improved. She now gets only occasional angina on excessive exertion, is much less dyspnoeic, and can get about comfortably and do 
some of her housework. The best result was obtainedin Case 2 (coronary sclerosis, angina pectoris). Before the operation the patient could walk only a few yards without being stopped by pain. $\mathrm{He}$ is now back at full heavy work, with little or no pain.

We think it fair to say that the two deaths from cerebral haemorrhage were secondary to the hypertension, which is not affected by the operation. The cardiac symptoms were improved in both, in one greatly. Of the remaining five cases two were failures, the others successful in varying degree, in one with return to full activity. When it is recalled that all seemed to be hopeless cases, in which every other form of treatment had failed, we feel that the measure of success attained has been gratifying. The two failures, however, show that further investigation is required in order to work out more clearly the indications for the operation.

\section{REFERENCES}

1 Anderson, J. P.: Amer. Heart Journ., 1932, viii, 128.

Andrus, E. C.: Ibid., 1932, viii, 66.

Andrus, E. C., and McEachern, D.: Amer. Journ. Med. Sci. 1932, clxxxiii, 741

4 Bach, F., and Bourne, G.: Quart. Journ. Med., 1932, i, 579

$\checkmark$ Barling, S.: Birmingham Med. Rev. June and September, 1932 - Barker. P. S., Bohning, A. L., and Wilson, F. N. Amer. Heart Journ., 1932, viii, 121 .

'Barland, A., and Donskowa, T.: Arch. des Mal. du Coeur, 1934, xxvii, 510 .

Berlin, D. D.: Amer. Journ. Surg., 1933, xxi, 173.

- Blumgart, H. L., Levine, S. A., and Berlin, D. D. Arch. Int. Med., 1923, li, 866

Med., 1923, li, 866

D., Riseman, J. E. F., Davis, D., and Berlin, D. D.: Ibid., 1933, lii, 165.

${ }^{21}$ Blumgart, H.' L., Berlin, D. D., Riseman, J. E. F., and Weinstein, A. A.: Ann. Int. Med., 1934, vii, 1469

${ }^{12}$ Boas, E. P.: Amer. Heart Journ., 1932, viii, 24

${ }^{3}$ Brenner, O., Donovan, H., and Murtagh, B. L. S.: British Medical Journal, 1934, ii, 624.

${ }^{4}$ Burnett, C. T., and Durbin, E.: Amer. Heart Journ., 1932, viii, 29.

15 Byrom, F. B.: Clin. Sci., 1934, i, 273.

16 Davis, A. C., and Smith, H. L.: Amer. Heart Journ., 1932, ix, 81.

${ }^{17}$ Davis, B., Weinstein, A. A., Riseman, J. E. F., and Blumgart, H. L.: Amer. Heart Journ., 1934, $\mathrm{x}, 17$.

18 Dock, W., and Lewis, J. K.: Journ. Physiol., 1932, lxxiv, 401.

${ }^{19}$ Don, C. S. D., and Langley, G. J.: Quart. Journ. Med., 1932, i, 9.

${ }^{20}$ Dunhill, T. P.: British Medical Journal, 1927, ii, 771.

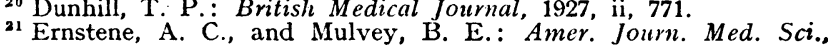
1934, clxxxviii, 383 .

${ }_{22}^{2}$ Fahr, G.: Amer. Heart Journ., 1932, viii, 91.

${ }^{23}$ Fraser, F. R.: British Medical Journal, 1931, ii, 739.

${ }_{24}^{24}$ Freedman, L. M.: Arch. Otolaryngol., 1934, xix, 383.

${ }^{5}$ Friedman, H. F., and Blumgart, H. L.: Journ. Amer. Med. Assoc., 1934, cri, 17.

${ }^{20}$ Gilligan, D. R., Berlin, D. D., Volk, M. C., Stern, B., and Blumgart, H. L. : Journ. Clin.'Invest., 1934, xiii, 789.

${ }^{27}$ Gilligan, D. R., Volk, M. C., Davis, D., and Blumgart: H. L.: Arch. Int. Med., 1934, liv.

${ }^{28}$ Goodall, J. S., and Rogers, L.: Lancet, 1927, i, 486

${ }^{29}$ Hamburger, Lev, Priest, and Howard: Arch. Int. Med., 1929, xliv, 35.

so Kepler, E. J., and Barnes, A. R.: Amer. Heart Journ., 1932, viii, 102.

${ }^{31}$ Lerman, J., and Means, J. H.: Ibid., 1932, viii, 55.

31 Lerman, J., and Means, J. H.: Ibid., 1932, viii, 55.
${ }^{32}$ Lerman, J., Clark, R. J., and Means, J. H.: Ann. Int. Med. 1933 ,

${ }^{33}$ Lev, M. Wi, W., and Hamburger, W. W.: Amer. Heart Journ., 1932, viii, 109

\$4 Idem: Ibid., 1932, viii, 134

${ }^{35}$ McGuire, J., and Foulger, M. : Ibid., 19:2, viii, 114.

36 Morris: Amer. Heart Journ., 1931, vi, 730.

${ }^{37}$ Ohler, W. R., and Abramson, J.: Arch. Int. Med., 1934, liii, 1c6.

s Parkinson, J., and Cockson, H.: Quart. Journ. Med., 1931, xxiv, 499.

${ }^{39}$ Parkinson, J., and Hoyle, C.: Lancet, 1934, ii, 913

40 Rake, G., and McEachearn, D.: Amer. Heart Journ., 1932 viii, 19.

1 Read, J. M. : Ibid., 1932, viii, 84

12 Rienhoff, W. F.: Medicine, 1931, x, 257

43 Romanis, W. H. C.: Bkitish Medical Journal, 1083, i, 87.

« Rosenblum, H. H., and Levine, S. A.: Amer. Journ. Med. $S c i .1933$, clxxxy, 219 .

cs Rosenblum, H., Hahn, E. G., and Levine, S. A.: Arch. Int. Med., 1933, li, 279.

46 Towers, J. R. H.: Lancet, 1933, i, 67

${ }^{47}$ Towers, J. R. H.: Lancet, 1933, i, 67.

"T Tung: Amer. Heart Journ., 1931, vi, 734. Amer. Journ. Med. Sci., 1934, clxxxvii, 753.

4 Weller, C. V., Wanstrom, R. C., Gordon, H., and Burgher, J. C. : Amer. Heart Journ., 1932, viii, 8.

so Yater, W. M.: Ibid., 1932, viii, 1.

${ }^{11}$ Means, J. H., and Lerman, J.: Arch. Int. Med., 1935, lv, 1.
RESULTS OF ÁNTE-NATAL ADMINISTRATION OF QUININE *

\author{
BY
}

PHILIP J. GANNER, M.B., B.S., F.R.C.S.

HONORARY OBSTETRIC SURGEON, BIRMINGHAM MATERNITY HOSPITAL: TUTOR IN MIDWIFERY AND DISEASES OF WOMEN, UNIVERSITY OF BIRMINGHAM

Although the idea of giving small doses of quinine during the last few weeks of pregnancy is by no means new, the literature on the subject is scanty. I have been- able to find only two papers in the English literature which give results and figures showing the effect on labour, although several others mention the method and claim certain advantages for it.

Mitchell ${ }^{1}$ described results of giving quin. sulph., $1 \frac{1}{2}$ grains t.d.s., during the last three weeks of pregnancy to a series of 400 cases spread over seven years. He made strong claims for the advantages of the method, which I quote verbatim:

" (a) The general health is improved.

" (b) Labour is made easier and shorter.

" (c) Uterine retraction' is uniformly good.

“ (d) There is no increased tendency to premature labour, precipitate labour, retained placenta, perineal laceration, or after-pains."

The author gave no detailed figures, but said that in "straightforward cases" duration of labour averaged six hours in primiparae and three in multiparae. The length of labour was ca!culated. from the onset of pain severe enough "to make the patient hold on to a chair."

Buddee $^{2}$ used a similar method at Queen Charlotte's in 100 cases. He gave details of the labours compared with controls. He found no support for Mitchell's claims, with the exception of a possible benefit to the patient's general health. It is noteworthy that whereas Mitchell referred only to " straightforward cases," the only cases excluded by Buddee were those of albuminuria and gross disproportion.

Such great disparity between the only two series of cases publishèd calls for further inquiry. If Mitchell's claims can be confirmed we have at our disposal a simple method of reducing the great dangers of everyday obstetricsnamely, the abuse of forceps, haemorrhage, and sepsis.

It appears to me that, in order to test the action of quinine on the uterus from the clinical point of view, it is necessary first of all to observe its effect on a series of cases which appeared normal during the ante-natal period. This should give an idea of the effect on the uterine action under conditions which are as near as possible to standard. If any beneficial result can be shown one may then consider the possible uses of the method in abnormal cases. But the inclusion of abnormal cases in the first series introduces so many varying factors that it becomes impossible to decide what part, if any, the quinine is playing.

\section{Material Reviewed and Results}

This short paper gives the results of the ante-natal use of quinine in fifty consecutive normal primiparae, with controls. By " normal" I mean cases which showed no abnormality whatever during the ante-natal period. Thus I have excluded all patients below the age of 18 and above 30, all cases where the head was not engaged by the thirty-eighth week of pregnancy, and also cases of albuminuria, heart disease, or other complications of pregnancy. All patients were given quinine bihydrochloride, 2 grains t.d.s., in tablet form, from the thirtysixth week of pregnancy onwards. The results obtained are shown below.

Onset and Duration of Labour.-The figures are taken from fifty cases in which labour started after the thirty-

* A paper read before the Midland Obstetrical and Gynaecological Society, May 20th, 1935. 